\title{
Application of Single Scan Differential Scanning Calorimetry Technique for Determination of Kinetic Parameters of Crystallisation in Se-Sb-Ag
}

\author{
Nidhi Yaduvanshi ${ }^{*}$, Deepak Kumar'1, Nikhil Rastogi ${ }^{2}$, Ashok Kumar ${ }^{3}$ \\ ${ }^{1}$ Department of Physics, JSS Academy of Technical Education, Noida, India \\ ${ }^{2}$ Department of Physics, IFTM University, Moradabad, India \\ ${ }^{3}$ Department of Physics, Harcourt Butler Technical University, Kanpur, India \\ Email: *nidhiyaduvanshi@jssaten.ac.in
}

How to cite this paper: Yaduvanshi, N., Kumar, D., Rastogi, N. and Kumar, A. (2019) Application of Single Scan Differential Scanning Calorimetry Technique for Determination of Kinetic Parameters of Crystallisation in Se-Sb-Ag. Journal of Crystallization Process and Technology, 9 , 1-11.

https://doi.org/10.4236/jcpt.2019.91001

Received: December 28, 2018

Accepted: January 27, 2019

Published: January 30, 2019

Copyright $\odot 2019$ by author(s) and Scientific Research Publishing Inc. This work is licensed under the Creative Commons Attribution-NonCommercial International License (CC BY-NC 4.0). http://creativecommons.org/licenses/by-nc/4.0/

\section{(c) (i) \& Open Access}

\begin{abstract}
A single scan has been performed in Differential Scanning Calorimetry (DSC) at a heating rate of $15^{\circ} \mathrm{C} / \mathrm{min}$ under non-isothermal conditions to investigate the crystallization kinetics of glassy $\mathrm{Se}_{90} \mathrm{Sb}_{10-x} \mathrm{Ag}_{x}$ alloys (where $x=2,4,6,8$ ). For this purpose, Handerson's theory based on non-isothermal method for thermal analysis of single-scan DSC data has been used. The activation energy of crystallization and order parameter has been determined and composition dependence of these parameters has been discussed.
\end{abstract}

\section{Keywords}

Differential Scanning Calorimetry, Crystallization, Order Parameter

\section{Introduction}

Chalcogenide glasses are of special interest due to their broad applications in modern electronics, optoelectronics, optics, electrophotography solar cells integrated optics, electrical and optical memory devices [1] [2] [3] [4] [5]. Selenium-based chalcogenide glasses have high transparency in the broad middle and far IR Region and have strong non linear properties and therefore Se has been found to have immense applications. A lot of Attempts have been made to improve Se properties by alloying it with other elements [6]. As these glasses have poor thermomechanical properties, it is necessary to increase their mechanical strength by addition of the third element to enlarge their domain prop- 
erties. Recent studies made on glass transition and crystallization kinetics of amorphous semiconductors provide interesting and important information on chalcogenides [7] [8] [9]. Crystallization of amorphous semiconductor is due to the simultaneous nucleation and growth of crystallites. Thus, crystal nucleation causes crystallization [10].

Different kinds of erasable phase-change optical recording materials have been investigated by several researchers. Some of the important properties of erasable phase-change optical recording materials are the laser power and pulse duration needed for writing and erasing, the maximum number of write/erase cycle and lifetime of recording spots at room temperature. In practice, the laser pulse duration used to write and erase is usually several hundred nanoseconds. It is difficult to erase a written spot in several hundred nano-seconds if the amorphous to crystalline $(\mathrm{a}-\mathrm{c})$ transformation rate of the recording medium is not sufficiently high. For this reason the study of crystallization rate and the factor that influence it are very important for the development of new kinds of erasable phase-change optical recording materials

Amorphous Selenium based chalcogenides have unique property of reversible transformation, making them useful for optical memory applications. Pure amorphous selenium is unstable because of its low glass transition temperature (about $42^{\circ} \mathrm{C}$ ) which is close to room temperature putting it in continuous danger of crystallization. Alloys of Se are very useful for various optical and photonic applications in the spectral range $0.6 \mu \mathrm{m}$ to $15 \mu \mathrm{m}$. These glasses have potential applications in solid-state devices [11] [12].

The kinetic of first-order phase transformation, such as crystallization, is important in physics, chemistry, ceramic and material science. Thermal analysis methods, including differential thermal analysis (DTA) are particularly important, since they are easy to be carried out and are quite sensitive. In DTA two basic methods can be used, isothermal and non-isothermal. In the isothermal method, the sample is brought quickly to a temperature above the glass transition temperature $\left(T_{g}\right)$ and the heat evolved during the crystallization process is recorded as a function of time while with non isothermal method, the sample is heated at fixed rate and the heat evolved is recorded as a function of temperature or time. While isothermal experimental analysis techniques are more definite but non-isothermal thermo-analytical techniques have several advantages. The rapidity, with which non-isothermal experiments can be performed, makes these experiments attractive. Non-Isothermal experiments can be used to extend the temperature range of measurements rather than the isothermal experiments. Many phase transformations occur too rapidly to be measured under isothermal conditions because of transitions inherently associated with the experimental apparatus. Industrial processes often depend on the kinetic behavior of systems undergoing phase transformation under non-isothermal conditions. In this respect, a definitive measurement of non-isothermal transformation kinetic is desirable. The phase transformation in chalcogenide glasses is studied by non-isothermal technique because of their usage in numerous applications in 
semiconductor.

Differential scanning calorimetry (DSC) techniques are sensitive, relatively easy to apply and require small sample quantities. In many cases, however, experimental studies of crystallization suffer from a lack of methods for quantitative analysis. This is particularly true for nonisothermal data, where most methods are based on erroneous assumptions [13].

Nucleation and growth described a large majority of Amorphous to crytallline (a-c) phase transformation which has been adopted. A study of a-c phase transformation is described by different methods [14]-[19]. This transformation is characterized by an activation energy $\Delta E_{c}$ and an Avrami exponent $\mathrm{n}$ according to the Johnson-Mehl-Avrami Kinetic Law. The determination of these parameters can be achieved in a relatively rapid and precise manner by non-isothermal DSC technique, which also allows an immediate observation of the transformation over a wider temperature range. Several DSC curves yields the product $n \Delta E_{c}$, when multiple scan technique is used for the analysis. Both these values can be determined separately by single scan technique which supplies $\Delta E_{d} / n$ and $\Delta E_{c}$ independently.

As is widely accepted that the addition of a third element to the binary chalcogenide glasses produces stability in these glasses, the effects of the elements as an additive to binary glasses have been extensively studied [20]. The present paper reports the crystallization in $\mathrm{Se}_{90} \mathrm{Sb}_{10-x} \mathrm{Ag}_{x}$ glasses using the DSC technique to understand the mechanism of crystallization in the alloy. Using single scan technique the activation energy $\Delta E_{c}$ and Avrami exponent $\mathrm{n}$ are calculated. Discussion of the composition dependence of these parameters has also been done.

\section{Experimental}

Glass composition $\mathrm{Se}_{90} \mathrm{Sb}_{10-x} \mathrm{Ag}_{x}(x=4,6,8)$ are prepared by melt quenching technique. The exact proportions of high purity (99.99\%) Se, Sb and Ag are weighed in accordance with their atomic percentages using an electronic balance (LIBROR, AEG-120) whose least count was $10^{-4} \mathrm{gm}$. The elements were heated together in an evacuated ( $10^{-5}$ Torr) quartz ampoule upto $1000^{\circ} \mathrm{C}$, so that it crosses the melting point of all the constituent's for 10 hours. The temperature of the furnace was raised slowly at a rate of $3-4^{\circ} \mathrm{C} /$ minute. Through the heating, the ampoule was frequently rocked for homogenization of the melt. The obtained melt was then rapidly quenched in ice-cooled water. The quenched sample was then taken out by breaking the quartz ampoule.

The glasses thus prepared were ground to make fine powder for DSC studies. In DSC, the sample is heated at a constant rate and the change in heat flow with respect to an empty reference pan is measured. The thermal behavior is studied using RIGAKU DSV MODEL 823B. In the scan the presence of well defined endothermic peaks at the glass transition temperature and an exothermic peak at the crystallization temperature is observed. The value of $T_{c}$ and $T_{g}$ were taken at the temperature corresponding to endothermic and exothermic peak respective- 
ly in DSC scan.

\section{Theory of Measurements}

The crystallization mechanism of amorphous materials is controlled by nucleation and growth process which can be characterized by activation energy " $\Delta E_{c}$ " and the Avrami exponent " $n$ " which is associated with the nucleation and growth mechanisms. According to John-Mehl-Avrami Law [21] [22] [23] the degree of crystallization is given by the following Equations:

$$
\alpha=1-\exp \left(K t^{n}\right)
$$

Here $\alpha$ is the extent of crystallization, $K$ is a function of temperature, In general the value of crystallization rate constant $K$ increases exponentially with temperature and hence can be given by

$$
K=K_{o} \exp \left(\frac{-\Delta E_{c}}{k T}\right)
$$

Here $\Delta E_{c}$ is the activation energy of crystallization and $\mathrm{k}$ is the Boltzmann's constant.

Crystallization kinectics of Chalcogenide glassy materials is a thermally activated process. Hendersan [24]-[29] has suggested single scan technique where non-isothermal DSC curve at a particular heating rate is analyzed. As per this theory the extent of crystallization is related to the activation energy of crystallization by the following equation:

$$
\frac{\mathrm{d}\left[\ln \left\{\ln (1-\alpha)^{-1}\right\}\right]}{\mathrm{d} T^{-1}}=\frac{-\Delta E_{c}}{k}
$$

It is clear from Equation (3) $\ln \left\{\ln (1-\alpha)^{-1}\right\}$ versus $T^{-1}$ plot should be a straight line and the activation energy $\Delta E_{c}$ involved in the molecular motion and rearrangements around $T_{c}$ can be calculated from slope of this plot.

$\Delta E_{d} n$ can be determined by the same theory proposed by Henderson. According to this theory the natural logarithm of first derivative of crystallization fraction can be expressed as:

$$
\ln \frac{\mathrm{d} \alpha}{\mathrm{d} t}=-\frac{\Delta E_{c}}{n k T}
$$

The derivation of above equation is

$$
\frac{\mathrm{d}(\mathrm{d} \alpha / \mathrm{d} t)}{\mathrm{d}\left(T^{-1}\right)}=-\frac{\Delta E_{c}}{n k}
$$

It is clear from Equation (5) that $\ln \frac{\mathrm{d} \alpha}{\mathrm{d} t}$ versus $T^{-1}$ should be a straight line and the slope gives $\Delta E_{d} / n$. The value of ' $n$ ' can be calculated if the value of $\Delta E_{c}$ is known from Equation (3).

\section{Results and Discussion}

From the DSC measurements of $\mathrm{Se}_{90} \mathrm{Sb}_{10-x} \mathrm{Ag}_{x}$ [30], at heating rate of $15^{\circ} \mathrm{C} / \mathrm{min}$, 
the value of $\alpha$ is calculated. Here $\alpha$ is the extent of crystallization and is calculated by dividing partial area to the total area of exothermic peak, i.e. $\alpha=A_{T} / A$. It is found that with temperature value of $\alpha$ with increases as shown in Figure 1.

Figure 2 shows plots between $\ln (\ln 1 /(1-\alpha))$ versus $1 / T$ which is a straight line for all the glassy alloys used, showing the validity of Equation (3). From the slopes of these graphs the values of $\Delta E_{c}$ is calculated for each glassy alloy. Table 1 shows these calculated values for all the glass alloys.
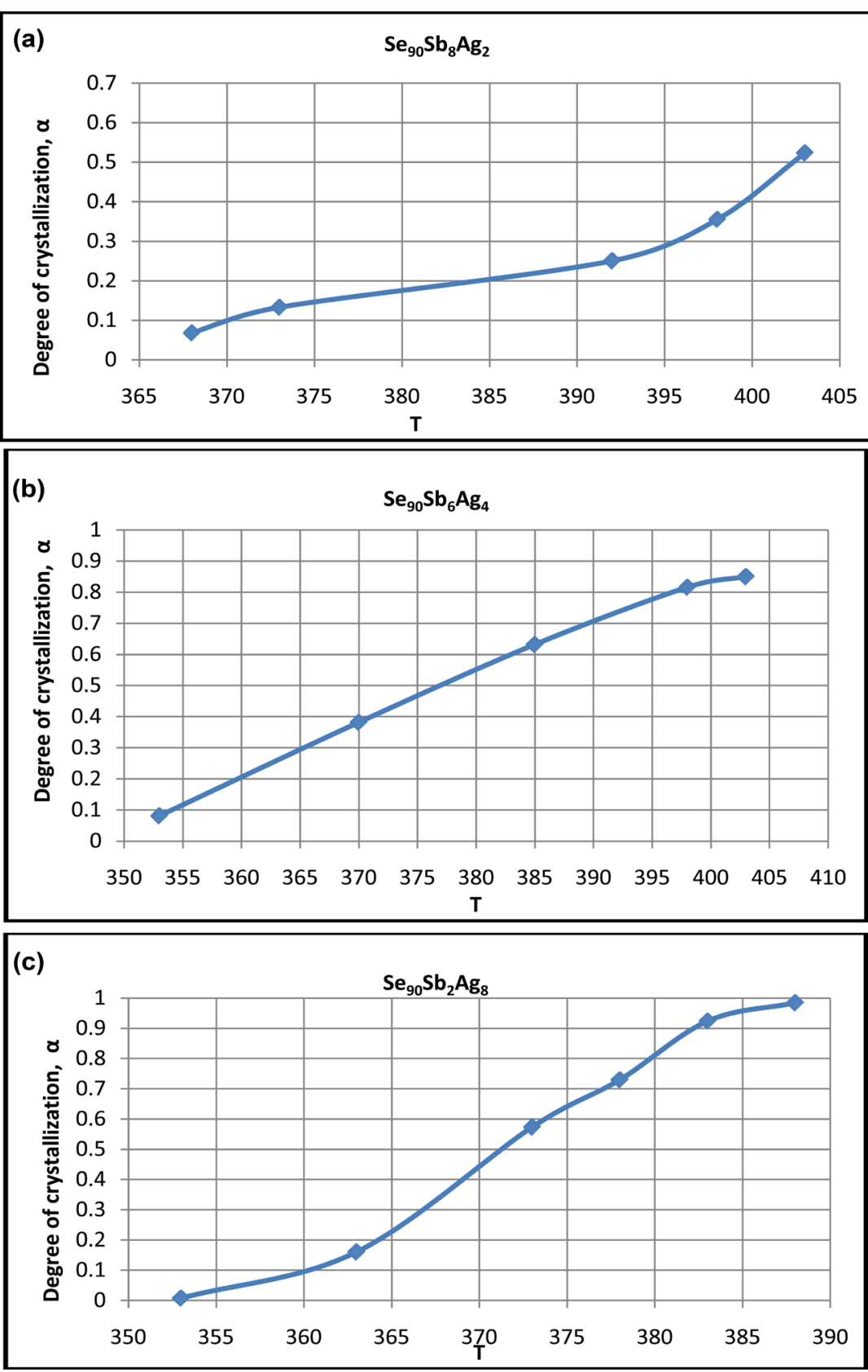

Figure 1. Degree of crystallization $(\alpha)$ versus temperature for $\mathrm{Se}_{90} \mathrm{Sb}_{10-x} \mathrm{Ag}_{x}$ glassy alloys. (a) Variation of Degree of crystallization ( $\alpha$ ) versus temperature (T) for $\mathrm{Se}_{90} \mathrm{Sb}_{8} \mathrm{Ag}_{2}$; (b) Variation of Degree of crystallization $(\alpha)$ versus temperature (T) for $\mathrm{Se}_{90} \mathrm{Sb}_{6} \mathrm{Ag}_{42}$; (c) Variation of Degree of crystallization ( $\alpha$ ) versus temperature (T) for $\mathrm{Se}_{90} \mathrm{Sb}_{2} \mathrm{Ag}_{8}$. 

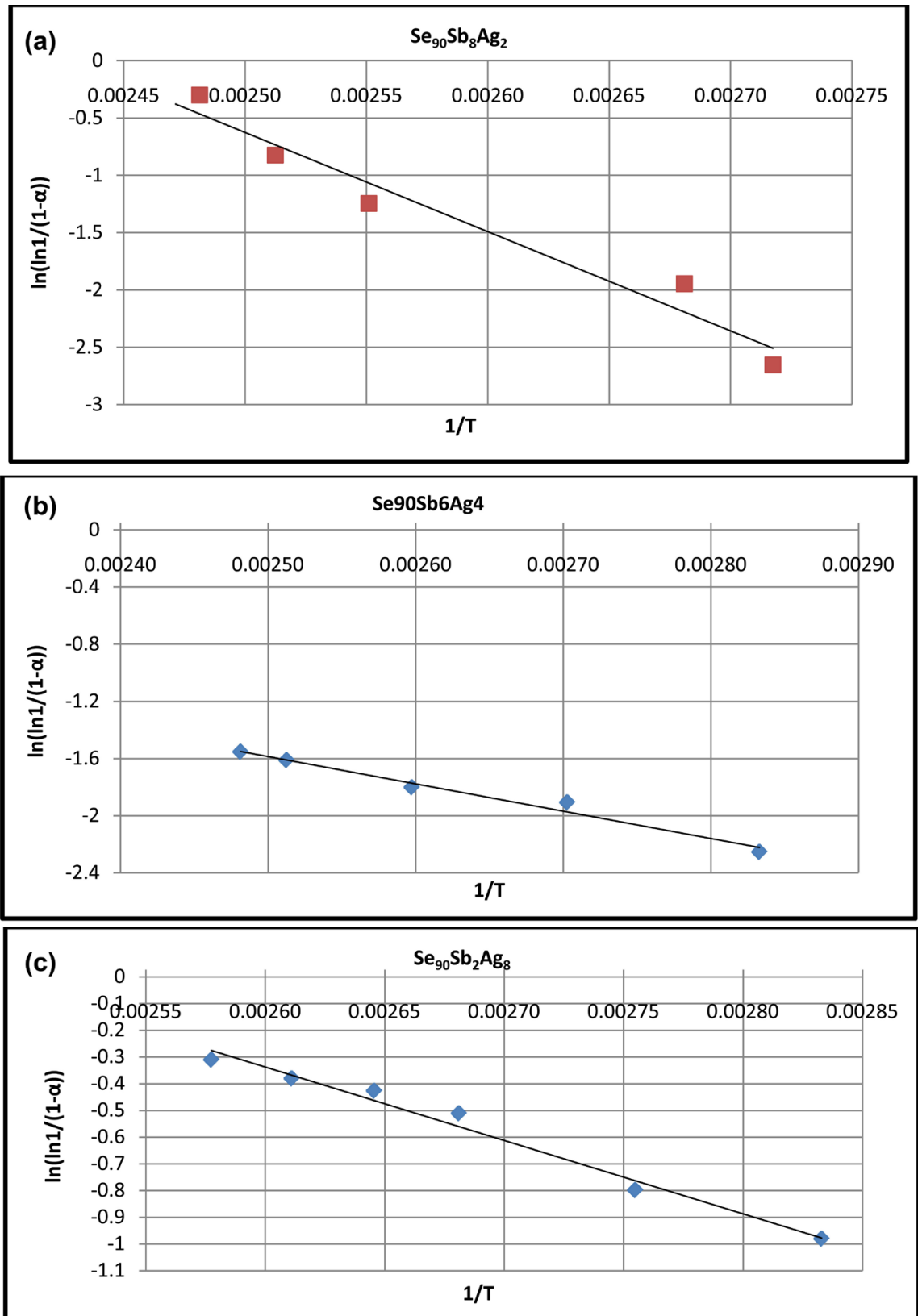

Figure 2. $\ln (\ln 1 /(1-\alpha))$ versus $1 / T$ curves for $\mathrm{Se}_{90} \mathrm{Sb}_{10-x} \mathrm{Ag}_{x}$ glassy alloys. (a) Variation of $\ln (\ln 1 /(1-\alpha))$ versus $1 / T$ for $\mathrm{Se}_{90} \mathrm{Sb}_{8} \mathrm{Ag}_{2}$; (b) Variation of $\ln (\ln 1 /(1-\alpha))$ versus $1 / T$ for $\mathrm{Se}_{90} \mathrm{Sb}_{6} \mathrm{Ag}_{4}$; (c) Variation of $\ln (\ln 1 /(1-\alpha))$ versus $1 / \mathrm{T}$ for $\mathrm{Se}_{90} \mathrm{Sb}_{10-x} \mathrm{Ag}_{x}$.

Table 1. Crystalization parameters $E_{c}$ and $n$ in a $\mathrm{Se}_{90} \mathrm{Sb}_{10-x} \mathrm{Ag}_{x}$ alloy.

\begin{tabular}{cccc}
\hline S. No. & Sample & $\mathrm{Ec}(\mathrm{KJ} / \mathrm{mole})$ & $\mathrm{n}$ \\
\hline 1. & $\mathrm{Se}_{90} \mathrm{Sb}_{8} \mathrm{Ag}_{2}$ & 71.5 & 0.2 \\
2. & $\mathrm{Se}_{90} \mathrm{Sb}_{6} \mathrm{Ag}_{4}$ & 72.1 & 0.5 \\
3. & $\mathrm{Se}_{90} \mathrm{Sb}_{2} \mathrm{Ag}_{8}$ & 138.9 & 1.01 \\
\hline
\end{tabular}

It is clear from this table that $\Delta E_{c}$ increases with $\mathrm{Ag}$ concentration and suddenly to a high value at 8 atomic percent of Ag. 
From the $\alpha$ versus $T$ curves as shown in Figure $1, \mathrm{~d} \alpha / \mathrm{d} T$ is calculated at various temperatures for each glassy alloy and $\mathrm{d} \alpha / \mathrm{d} t$ is calculated by multiplying $\mathrm{d} \alpha / \mathrm{d} T$ to the heating rate $(\beta)$.

Figure 3 shows plots of $\mathrm{d} \alpha / \mathrm{d} t$ as function of $1 / T$ for all glassy alloys studied here. It is clear from these figures that such plots are straight lines, showing the validity of Equation (5). Values of $\Delta E_{d} / n$ are calculated from the slopes of these curves for all glassy alloys used. Using the value of $\Delta E_{c}$ calculated above (as shown in Table 1), and order parameter $(n)$ is calculated for each glassy alloy
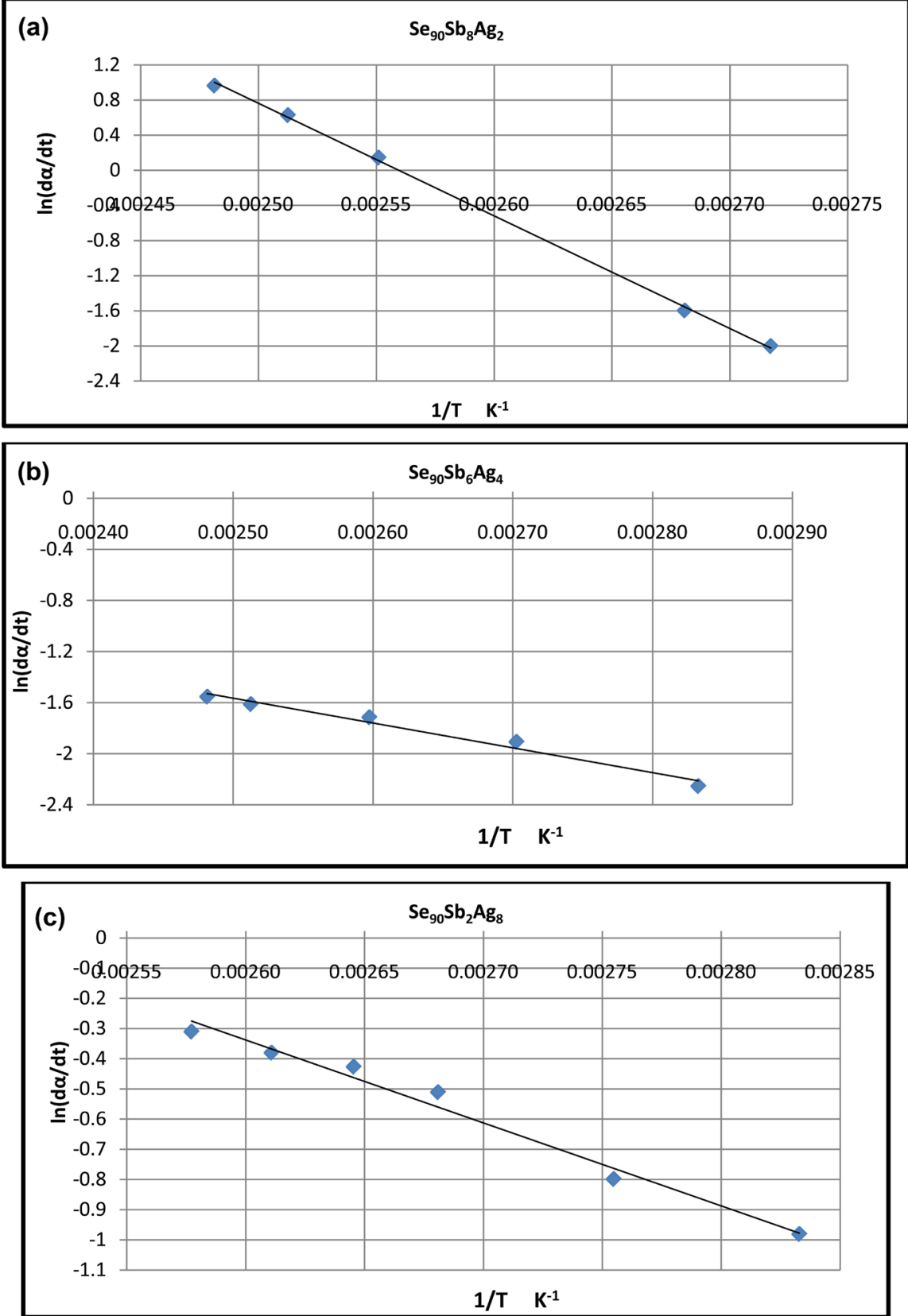

Figure 3. $\ln (\mathrm{d} \alpha / \mathrm{d} t)$ versus $1 / T$ for $\mathrm{Se}_{90} \mathrm{Sb}_{10-x} \mathrm{Ag}_{x}$ glassy alloy. (a) Variation of $\ln (\mathrm{d} \alpha / \mathrm{d} t)$ versus $1 / T$ for $\mathrm{Se}_{90} \mathrm{Sb}_{8} \mathrm{Ag}_{2}$; (b) Variation of $\ln (\mathrm{d} \alpha / \mathrm{d} t)$ versus $1 / T$ for $\mathrm{Se}_{90} \mathrm{Sb}_{6} \mathrm{Ag}_{4}$; (c) Variation of $\ln (\mathrm{d} \alpha / \mathrm{d} t)$ versus $1 / T$ for $\mathrm{Se}_{90} \mathrm{Sb}_{10-x} \mathrm{Ag}_{x}$ 
and values are given in Table 1. It is clear from the table that the value of $\mathrm{n}$ are near to 1 for all the glasses studied, indicating one dimensional crystal growth in these alloys.

The thermal stability [31] and glass forming tendency (GFT) is an important feature of chalcogenide alloys which is useful as recording materials due to the fact that phase-change optical recording and erasing techniques are based on the laser-induced thermal amorphization and crystallization of chalcogenide glasses. This develops interest [32] [33] [34] [35] in the study of thermal stability and GFT. Recently some work has been done in this area [36] [37]. $T_{g}$ determines the strength and rigidity of the glass structure in chalcogenides. The difference between $T_{c}$ and $T_{g}$ provides complete imformation about thermal stability as well as GFT. Higher is value of $\left(T_{c}-T_{g}\right)$, greater is the GFT, because it delays the nucleation process [37]. Using the peaks of endothermic and exothermic peaks of $T_{g}$ and $T_{\mathcal{o}}$ The values of $\left(T_{c}-T_{g}\right)$, are calculated from DSC Scans and given in Table 2.

Figure 4 shows plots of thermal stability $\left(T_{c}-T_{g}\right)$ versus Ag concentration. It is observed from the graph that, $T_{c}-T_{g}$ first decreases and then increases with Ag concentration, which confirms maximum stability of $\mathrm{Se}_{90} \mathrm{SbAg}_{8}$. Hence, one can conclude that the activation energy of glass transition process is related to thermal stability and GFT. Compositional dependence of thermal stability shows a discontinuity at an $\mathrm{Ag}$ concentration of $8 \%$, which is explained in terms of mechanically optimised structure at a particular average coordination number.

\section{Conclusions}

Calorimetric studies have been made in glassy $\mathrm{Se}_{90} \mathrm{Sb}_{10-x} \mathrm{Ag}_{x}$ alloys. Single scan

Table 2. Thermal stability in glassy $\mathrm{Se}_{90} \mathrm{Sb}_{10-x} \mathrm{Ag}_{x}$ alloy.

\begin{tabular}{ccc}
\hline \multicolumn{3}{c}{ Heating rate $15^{\circ} \mathrm{C} / \mathrm{min}$} \\
\hline S. No. & Glassy Alloy & $T_{C}-T_{g}$ \\
\hline 1. & $\mathrm{Se}_{90} \mathrm{Sb}_{8} \mathrm{Ag}_{2}$ & 60.6 \\
2. & $\mathrm{Se}_{90} \mathrm{Sb}_{6} \mathrm{Ag}_{4}$ & 59.4 \\
3. & $\mathrm{Se}_{90} \mathrm{SbAg}_{8}$ & 91.6 \\
\hline
\end{tabular}

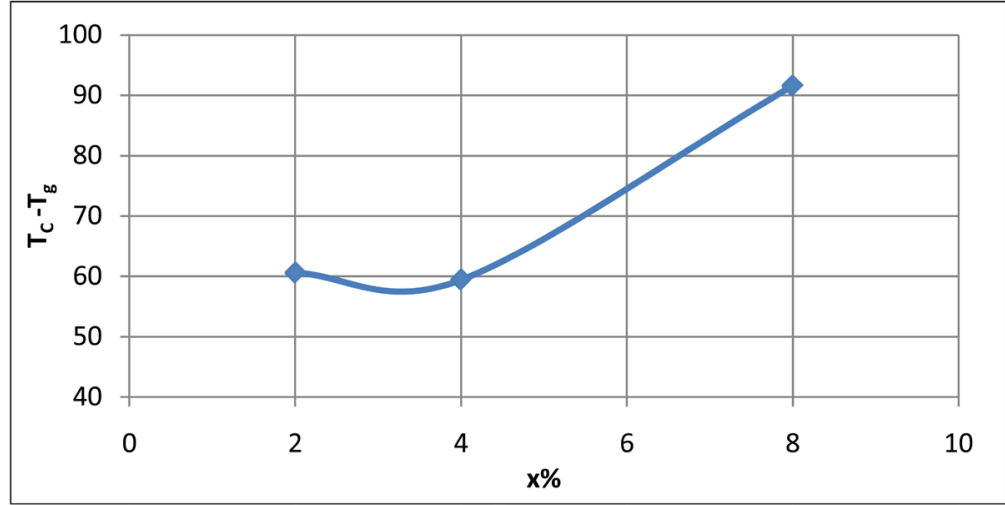

Figure 4. Variation of $T_{c}-T_{g}$ with Ag concentration in $\mathrm{Se}_{90} \mathrm{Sb}_{10-x} \mathrm{Ag}_{x}$ alloys. 
technique has been used to calculate the Activation energy of crystallization $\Delta E_{\mathcal{c}}$ order parameter $(n)$ and thermal stability $\left(T_{c}-T_{g}\right)$. The results show that $\Delta E_{c}$ is highly composition dependent. Thermal stability is also reported at various concentration of $\mathrm{Ag}$ and is maximum for $\mathrm{Se}_{90} \mathrm{Sb}_{2} \mathrm{Ag}_{8}$ alloy. It decreases and then increases with higher concentration of $\mathrm{Ag}$ showing minima at 4 atomic percent of Ag.

The value of Avrami index $n$ is varying upto 1 for all glassy alloys studied, which indicates one-dimensional crystal growth during amorphous to crystalline transformation of $\mathrm{Se}_{90} \mathrm{Sb}_{10-x} \mathrm{Ag}_{x}$ alloys.

\section{Conflicts of Interest}

The authors declare no conflicts of interest regarding the publication of this paper.

\section{References}

[1] Ohta, T. (2001) Phase-Change Optical Memory Promotes the DVD Optical Disk. Journal of Optoelectronics and Advanced Material, 3, 609-626.

[2] Ovshinsky, S.R. (1968) Reversible Electrical Switching Phenomena in Disordered Structures. Physical Review Letters, 21, 1450. https://doi.org/10.1103/PhysRevLett.21.1450

[3] Seddon, A.B. and Laine, M.J. (1997) Chalcogenide Glasses for Acousto-Optic Devices. II. As-Ge-Se Systems. Journal of Non-Crystalline Solids, 213, 168-173. https://doi.org/10.1016/S0022-3093(96)00665-5

[4] Kolobov, A.V. and Tominaga, J. (2002) Chalcogenide Glasses in Optical Recording: Recent Progress. Journal of Optoelectronics and Advanced Materials, 4, 679-686.

[5] Andriesh, A.M., Iovu, M.S. and Shutov, S.D. (2002) Chalcogenide Non-Crystalline Semiconductors in Optoelectronics. Journal of Optoelectronics and Advanced Materials, 4, 631-647.

[6] Parveen, B., et al. (2018) Investigation of Physical Properties of SnS: Fe Diluted Magnetic Semiconductor Nanoparticles for Spintronic Applications. Journal of Magnetism and Magnetic Materials, 460, 111-119. https://doi.org/10.1016/j.jmmm.2018.03.022

[7] Debenedetti, P.G. and Stillinger, F.H. (2001) Supercooled Liquids and the Glass Transition. Nature, 410, 259-267. https://doi.org/10.1038/35065704

[8] Angell, C.A., Ngai, K.L., McKenna, G.B., McMillan, P.F. and Martin, S.W. (2000) Relaxation in Glassforming Liquids and Amorphous Solids. Journal of Applied Physics, 88, 3113-3157. https://doi.org/10.1063/1.1286035

[9] Angell, C.A. (1995) Formation of Glasses from Liquids and Biopolymers. Science, 267, 1924-1935. https://doi.org/10.1126/science.267.5206.1924

[10] Wamwangi, D., Njoroge, W.K. and Wuttig, M. (2002) Crystallization Kinetics of $\mathrm{Ge}_{4} \mathrm{Sb}_{1} \mathrm{Te}_{5}$ Films. Thin Solid Films, 408, 310-315. https://doi.org/10.1016/S0040-6090(02)00062-7

[11] Mehta, N. and Kumar, A. (2006) Comparative Analysis of Calorimetric Studies in $\mathrm{Se}_{90} \mathrm{M}_{10}(M=\mathrm{In}, \mathrm{Te}, \mathrm{Sb})$ Chalcogenide Glasses. Journal of Thermal Analysis and Calorimetry, 87, 345-350. https://doi.org/10.1007/s10973-005-7411-3

[12] Singh, A.K. and Kedar, S. (2007) Correlative Study of Optical, Electrical and Ther- 
mal Transport Properties of $\mathrm{Se}_{100-\mathrm{x}} \mathrm{In}_{\mathrm{x}}$ Chalcogenide Glasses. Journal of Optoelectronics and Advanced Materials, 9, 3756-3759.

[13] Gao, Y.Q. and Wang, W. (1986) On the Activation Energy of Crystallization in Metallic Glasses. Journal of Non-Crystalline Solids, 81, 129-134.

https://doi.org/10.1016/0022-3093(86)90262-0

[14] Bhargavaf, A. (2010) Crystallization Process in Amorphous Sn-Te-Se Thin Films. Chalcogenide Letters, 7, 175-180.

[15] Mehta, N., Dwivedi, V., Agnihotari, A.K. and Kumar, A. (2017) Applicability of Single-Scan Differential Scanning Calorimetry Technique for Determination of Kinetic Parameters of Crystallization in Glassy Se-Te-Ga System. Advanced Science, Engineering and Medicine, 9, 311-314. https://doi.org/10.1166/asem.2017.2008

[16] Saffarini, G., Saiter, J.M. and Schmitt, H. (2007) The Composition Dependence of the Optical Band Gap in Ge-Se-In Thin Films. Optical Materials, 29, 1143-1147. https://doi.org/10.1016/j.optmat.2006.05.003

[17] Moharram, A.H., El-Oyoun, M.A. and Abu-Sehly, A.A. (2001) Calorimetric Study of the Chalcogenide $\mathrm{Se}_{72.5} \mathrm{Te}_{20} \mathrm{Sb}_{7.5}$ Glass. Journal of Physics D: Applied Physics, 34, 2541. https://doi.org/10.1088/0022-3727/34/16/321

[18] Anami, B. and Kalla, J. (2016) DTA and Thermal Stability Study of Se-Te-Sn Glass. International Journal of Materials Science and Engineering, 4, 126-132.

[19] Jaakko, A., et al. (2009) Solid Form Screening-A Review. European Journal of Pharmaceutics and Biopharmaceutics, 71, 23-37. https://doi.org/10.1016/j.ejpb.2008.07.014

[20] Atyia, H.E. and Bekheet, A.E. (2008) Switching Phenomenon and Optical Properties of $\mathrm{Se}_{85} \mathrm{Te}_{10} \mathrm{Bi}_{5}$ Films. Physica B: Condensed Matter, 403, 3130-3136. https://doi.org/10.1016/j.physb.2008.03.029

[21] Henderson, D.W. (1979) Experimental Analysis of Non-Isothermal Transformations Involving Nucleation and Growth. Journal of Thermal Analysis, 15, 325-331. https://doi.org/10.1007/BF01903656

[22] Melvin, A. (1939) Kinetics of Phase Change. I General Theory. The Journal of Chemical Physics, 7, 1103-1112. https://doi.org/10.1063/1.1750380

[23] Melvin, A. (1940) Kinetics of Phase Change. II Transformation Time Relations for Random Distribution of Nuclei. The Journal of Chemical Physics, 8, 212-224. https://doi.org/10.1063/1.1750631

[24] Kissinger, H.E. (1956) Variation of Peak Temperature with Heating Rate in Differential Thermal Analysis. Journal of Research of the National Bureau of Standards, 57, 217-221. https://doi.org/10.6028/jres.057.026

[25] Kissinger, H.E. (1957) Reaction Kinetics in Differential Thermal Analysis. Analytical Chemistry, 29, 1702-1706. https://doi.org/10.1021/ac60131a045

[26] Matusita, K., Takayama, S. and Sakka, S. (1980) Electrical Conductivities of Mixed Cation Glasses. Journal of Non-Crystalline Solids, 40, 149-158. https://doi.org/10.1016/0022-3093(80)90099-X

[27] Sestak, J. (1974) Applicability of DTA to the Study of Crystallization Kinetics of Glasses. Physics and Chemistry of Glasses, 15, 137-140.

[28] Boswell, P.G. (1980) The Effect of Thermal History on the Crystallization Kinetics of a Liquid-Quenched Metallic Glass. Journal of Materials Science, 15, 1926-1938. https://doi.org/10.1007/BF00550618

[29] Henderson, D.W. (1979) Thermal Analysis of Non-Isothermal Crystallization Kinetics in Glass Forming Liquids. Journal of Non-Crystalline Solids, 30, 301-315. 
https://doi.org/10.1016/0022-3093(79)90169-8

[30] Srivastava, N.M., Kumar, D. and Kumar, A. (2013) Crystallisation in Glass Transition Kinectics in $\mathrm{Se}_{90} \mathrm{Sb}_{10-\mathrm{x}} \mathrm{Ag}_{\mathrm{x}}$ Glassy Alloys. Iraqi Journal of Applied Physics, 9 , 7-13.

[31] Sunil, K. and Singh, K. (2012) Glass Transition, Thermal Stability and Glass-Forming Tendency of $\mathrm{Se}_{90-\mathrm{x}} \mathrm{Te}_{5} \mathrm{Sn}_{5} \mathrm{In}_{\mathrm{x}}$ Multi-Component Chalcogenide Glasses. Thermochimica Acta, 528, 32-37. https://doi.org/10.1016/j.tca.2011.11.005

[32] Manish, S. (2005) A Crystallization Study of Amorphous $\mathrm{Te}_{\mathrm{x}}\left(\mathrm{Bi}_{2} \mathrm{Se}_{3}\right)_{1-\mathrm{x}}$ Alloys with Variation of the Se Content. Journal of Physics D: Applied Physics, 38, 460. https://doi.org/10.1088/0022-3727/38/3/017

[33] Mehta, N., Kumar, D. and Kumar, A. (2007) Correlation between Glass Forming Tendency and Rate of Crystallization in Glassy $\mathrm{Se}_{100-\mathrm{x}} \mathrm{Te}_{\mathrm{x}}$ and $\mathrm{Se}_{100-\mathrm{x}} \mathrm{In}_{\mathrm{x}}$ Alloys. Physica Status Solidi, 204, 3108-3115.

[34] Anjani, K., Shukla, S. and Shukla, R.K. (2017) Electrical, Photo-Electrical and Optical Properties of Selenium Rich Chalcogenide Glasses: A Review. Materials Focus, 6, 415-423. https://doi.org/10.1166/mat.2017.1425

[35] Mehta, N., Agarwal, P. and Kumar, A. (2005) Calorimetric Studies of Glass Forming Ability and Thermal Stability in A-Se $e_{80} \mathrm{Te}_{19.5} \mathrm{M}_{0.5}(\mathrm{M}=\mathrm{Ag}, \mathrm{Cd}, \mathrm{In}, \mathrm{Sb})$ Alloys. The European Physical Journal-Applied Physics, 31, 153-158. https://doi.org/10.1051/epjap:2005048

[36] Mehta, N. and Kumar, A. (2004) Thermal Characterization of Glassy $\mathrm{Se}_{70} \mathrm{Te}_{20} \mathrm{M}_{10}$ Using DSC Technique. Journal of Materials Science, 39, 6433-6437. https://doi.org/10.1023/B:JMSC.0000044880.99215.be

[37] Saxena, N.S. (2004) Phase Transformation Kinetics and Related Thermodynamic and Optical Properties in Chalcogenide Glasses. Journal of Non-Crystalline Solids, 345, 161-168. https://doi.org/10.1016/j.jnoncrysol.2004.08.016 